\title{
Contemporary Carbon Content of Bis (2-ethylhexyl) Phthalate in Butter
}

\author{
T. Tong ${ }^{1}$, J. M. Ondov ${ }^{2}$, B. A. Buchholz ${ }^{3}$, M. C. VanDerveer ${ }^{4}$ \\ ${ }^{1,2}$ Department of Chemistry and Biochemistry, University of Maryland, College Park, \\ MD 20742, USA \\ ${ }^{3}$ Center for Accelerator Mass Spectrometry, Lawrence Livermore National Laboratory, \\ Livermore, California 94551, USA \\ ${ }^{4}$ U.S. Food and Drug Administration, University Station, College Park, MD 20740, USA
}

\begin{abstract}
The fraction of naturally produced Bis (2-ethylhexyl) phthalate (DEHP), a ubiquitous plasticizer known to contaminate packaged foods, was determined for each of five $1.10 \mathrm{~kg}$ samples of unsalted market butter by accelerator mass spectrometry (AMS). After extraction and concentration enrichment with liquid-liquid extraction, flash column chromatography, and preparative-scale high performance liquid chromatography, each sample provided $\approx 250 \mu \mathrm{g}$ extracts of DEHP with carbon purity ranging from $92.5 \pm 1.2 \%$ $(\mathrm{n}=3,1 \sigma)$ to $97.1 \pm 0.8 \%(\mathrm{n}=3,1 \sigma)$ as measured with gas chromatography mass spectrometry (GC-MS). After corrections for method blank DEHP, co-eluting compounds, and unidentified carbon, the mean fraction of naturally produced DEHP in butter was determined to be $0.16 \pm 0.12(n=5,1 \sigma)$. To our knowledge, this is the first report of the contemporary fraction of DEHP isolated from market butter in the U.S.
\end{abstract}

Keywords: DEHP, AMS, Monte Carlo simulation, fraction modern, phthalate 


\section{Introduction}

With an annual worldwide production of 1 to 4 million metric tons (Pocar, Fiandanese, Secchi, Berrini, Fischer, Schmidt, et al., 2012), Bis (2-ethylhexyl) Phthalate (DEHP) is the most widely used commercial plasticizer. It is commonly used as a softener to improve material flexibility in plastic pipes (up to $30 \%$ in PVC by mass) (European Chemicals Bureau, 2008), tubing (including those used in medical procedures), packing materials (including those used in food packaging) (Rudel, Gray, Engel, Rawsthorne, Dodson, Ackerman, et al., 2011); and as a thickener in cosmetics, personal care products (Koo \& Lee, 2004), and printing inks (including those used in food-wrap labels) (Nerin, Cacho, \& Gancedo, 1993). DEHP is a viscous liquid at room temperature and is not covalently bonded to polymeric matrices. Therefore it readily diffuses from plastics and various other products into blood used in transfusions, food, and drinks (Rais-Bahrami, Nunez, Revenis, Luban, \& Short, 2004). Approximately $2 \%$ of the global phthalate production is released into the environment each year and part of this release is incorporated into the food chain (Huber, Grasl-Kraupp, \& Schulte-Hermann, 1996).

In addition to its anthropogenic production, algae and certain microorganisms synthesize DEHP naturally. Chen (2004) found that the red alga, Bangia atropurpurea, from shallow costal waters of Taiwan, synthesized DEHP, de novo, as evidenced by cultivating it in the laboratory with $\mathrm{NaH}^{14} \mathrm{CO}_{3}$ (Chen, 2004). Japanese scientists, Hayashi et al. (1967) found phthalates in Cryptotaenia Canadensis DC. Var. Jayonic Makino, a perennial vegetable cultivated in Japan, albeit the sources of these phthalates were not 
well established (Hayashi, Asakawa, Ishida, \& Matsuura, 1967). Some fungi also synthesize DEHP. For example, Penicillium olsonii produces DEHP as a metabolite (Amade, Mallea, \& Bouaicha, 1994). As algae and other microbes are widely used in herd forage, incorporation into dairy products is possible.

DEHP has a low acute toxicity and can be metabolized quickly in humans. In fact, $47 \%$ of the DEHP ingested is excreted in urine after metabolic hydroxylation and hydrolysis to produce mono (2-ethyl-5-hydroxyhexyl) phthalate, mono (2-ethyl-5-oxohexyl) phthalate, and mono (2-ethylhexyl) phthalate (MEHP), within two days after ingestion (Koch, Bolt, $\&$ Angerer, 2004). Nevertheless, evidence suggests that both high-level acute and chronic exposures to DEHP (up to $0.05 \%$ of diet mass) have induced hepatic tumorigenesis in mice (Ito, Yamanoshita, NAsaeda, Tagawa, Lee, Aoyama, et al., 2007), infertility by endocrine function disruption in female rats $\left(1.4 \mathrm{~g} \mathrm{~kg}^{-1}\right.$ body mass, twice per week for 26 weeks) (Hirosawa, Yano, Suzuki, \& Sakamoto, 2006), and male feminization in humans (Lottrup, Andersson, Leffers, Mortensen, Toppari, Skakkebaek, et al., 2006)

According to the U.S. Department of Health and Human Services (DHHS), prior to 2002, inhalation of contaminated indoor air, ingestion of contaminated water and food, and exposure to DEHP from plastic medical products were the dominant pathways leading to human exposure of DEHP (Agency for Toxic Substances and Disease Registry, 2002). Although the usage of DEHP has been voluntarily reduced in food contact materials, phthalate esters are still found in foods (Alderson, 2008). Prior to 2002, the daily DEHP intake from food in the U.S. was reported to be $5.8 \mathrm{mg}$ (Giust, Seipelt, Anderson, Deis, \& Hinders, 1990). In 2011, DHHS reported daily DEHP intake (1-30 $\mu \mathrm{g} / \mathrm{kg}$ body weight) equivalent to be at most $2.2 \mathrm{mg}$ (Department of Health and Human Services, 2011). 
Despite this reduction in dose, the issue of phthalates in food matrices remains of concern to the US-FDA, provided that naturally occurring biochemical processes do not synthesize the phthalates in food.

Carbon in compounds synthesized by the biogenic processes of living organisms contain approximately one part per trillion of radiocarbon $\left({ }^{14} \mathrm{C}\right)$ owing to incorporation of ${ }^{14} \mathrm{CO}_{2}$ formed in the upper-atmosphere by oxidation of ${ }^{14} \mathrm{C}$ produced by cosmic neutron reactions on ${ }^{14} \mathrm{~N} .{ }^{14} \mathrm{C}$ decays with a half-life of $5730 \pm 40$ years (Cambridge half-life, 1962). As virtually all commercially-produced DEHP is made from petrochemical feedstocks that have been isolated from the atmosphere for millions of years, petrochemically derived DEHP contains ${ }^{14} \mathrm{C} / \mathrm{C}<10^{-15}$. As demonstrated by Eglinton et al. (1997), the abundance of ${ }^{14} \mathrm{C}$ in individual compounds in complex matrices can be determined by compound-specific Accelerator Mass Spectrometry (CS-AMS) (Eglinton, Benitez-Nelson, Pearson, McNichol, Bauer, \& Druffel, 1997).

CS-AMS has been applied to DEHP isolated from three strains of algae: Undaria pinnatifida, Laminaria japonica and Ulva sp.(Namikoshi, Fujiwara, Nishikawa, \& Ukai, 2006), and more recently DEHP isolated from Stilton Cheese, a cheese injected with penicillium (Nelson, Ondov, VanDerveer, \& Buchholz, 2013). Results from the former suggest that large fractions of the DEHP extracted from algae (49.8 to $87.2 \%$ ) were synthesized by natural biogenic processes. The latter suggests that a significant fraction $(23.5 \pm 7.3 \%)$ of the DEHP in Stilton Cheese could be attributable to natural biogenic processes, possibly owing to production by penicillium $s p$. 
Butter contains the highest mean level of lipids $(81.1 \% \mathrm{w} / \mathrm{w})$ in dairy products (U.S. Department of Agriculture, 2013). DEHP concentrations in butter as great as $2.4 \mathrm{mg} / \mathrm{kg}$ have been reported (Sharman, Read, Castle, \& Gilbert, 1994). By our own analyses, the average DEHP content in recently purchased Giant-brand unsalted butter was $0.70 \pm 0.03$ $\mathrm{mg} / \mathrm{kg}(\mathrm{n}=4,1 \sigma)$. Since butter is neither fermented nor contains mold, bacteria, or algae, the natural abundance of ${ }^{14} \mathrm{C}$ in its DEHP could be expected to be less than that found in Stilton cheese. For these reasons, and to further develop the data available for the origin of DEHP in fatty food, CS-AMS was applied to DEHP isolated from several batches of market butter.

\section{Methods}

\subsection{Extraction and Enrichment}

Five 1.10-kg batches of butter (Giant, unsalted, distributed by Foodhold USA, Inc., Landover, MD 20785) were extracted with hexane and purified with flash chromatography and preparative-scale HPLC to obtain $\approx 250 \mu$ g DEHP per batch. Three method blanks were simultaneously prepared to determine DEHP contamination resulting from the solvents, column packings, and contact with surfaces of the apparatuses. Approximately $570 \mu \mathrm{g}$ of fully deuterated $d 38$-DEHP (98\% pure, Cambridge Isotope Laboratories, Andover, MA) were spiked into both butter batches and method blanks at the very beginning to determine the yields and to assist identification of peaks in the HPLC chromatograms.

For each batch, the butter was dissolved in $1.0 \mathrm{~L}$ hexane (J. T. Baker, 95\% n-Hexane) with gentle heat $\left(\approx 40^{\circ} \mathrm{C}\right)$. The supernatant fluid was removed by gravity filtration. The 
material remaining insoluble was then extracted with $300 \mathrm{~mL}$ of $17 \% \mathrm{v} / \mathrm{v}$ acetone (Sigma Aldrich, ACS reagent, $\geq 99.5 \%$ ) in hexane and filtered. Both of these filtered extracts were combined and reduced to $1200 \mathrm{~mL}$ with rotary evaporation. DEHP is nearly 7 -fold more soluble in acetonitrile than saturated fatty acid esters (Zhou, Chen, \& Li, 2002) (Kotowska, Garbowska, \& Isidorov, 2006). Therefore, each $400 \mathrm{~mL}$ extract was mixed with 1.0 L acetonitrile (J. T. Baker, HPLC grade, 99.9\%) for solvent-solvent partitioning. After partitioning the resulting 3-L, light-yellow, DEHP-enriched-acetonitrile layer was reduced to $1.0 \mathrm{~L}$ and stored in a freezer $\left(-20^{\circ} \mathrm{C}\right)$ for $12 \mathrm{~h}$. Lipids and proteins precipitated after cooling and were removed by gravity filtration. Solvent was removed from the filtrate by rotary evaporation and the residual was retrieved in $4 \mathrm{~mL}$ hexane for subsequent purification. Each butter extract was split into four 1-mL fractions for processing on a newly-packed flash column with silica gel (32 to $63 \mu \mathrm{m}$, Dynamic Adsorbents, Atlanta, GA) and eluted with a $1.6 \% \mathrm{v} / \mathrm{v}$ mixture of acetone in hexane under pressure of charcoal-scrubbed (model 300 high-pressure hydrocarbon trap, Chromatography Research Supplies, Louisville, KY) and filtered (Swagelok stainless steel in-line particle filter) compressed air. The DEHP fraction was collected between $1100 \mathrm{~mL}$ and $1500 \mathrm{~mL}$ of the mobile phase, as verified by gas chromatography-electronimpact-mass spectrometry (GC-EIMS) (Shimadzu ${ }^{\circledR}$ QP2010S, Shimadzu ${ }^{\circledR}$ SHRXI-5MS column, $30 \mathrm{~m}, 0.25 \mu \mathrm{S}$ I.D., polysiloxane coated). All DEHP-containing eluates were combined to yield $1600 \mathrm{~mL}$ (per $1.1 \mathrm{~kg}$ butter sample) of hexane solution, dried, and redissolved in $1 \mathrm{~mL}$ of acetonitrile for preparative-scale HPLC.

A Hewlett-Packard series 1050 HPLC with a C18 column $\left(15 \mathrm{~cm} \times 9.4 \mathrm{~mm}-\mathrm{ID}\right.$, Agilent ${ }^{\circledR}$ Zorbax Eclipse) was used for further purification. To achieve a reasonable resolution 
( $\mathrm{R}=1.1$ ) between $\mathrm{d} 38$-DEHP and DEHP, gradient elution was applied starting with $90 \%$ acetonitrile and $10 \%$ water at $30^{\circ} \mathrm{C}$ at $4 \mathrm{~mL} / \mathrm{min}$. After $10 \mathrm{~min}$, the mobile phase composition was adjusted to $95 \%$ acetonitrile and $5 \%$ water, and elution continued at the same temperature and flow rate. The instrument's diode array detector (DAD) was set to 254 nm, the maximum absorbance of DEHP (Orsi, Gagliardi, Porrà, Berri, Chimenti, Granese, et al., 2006). d38-DEHP and DEHP were eluted at 19 and 21 min, respectively. Eluates were collected in aluminum-foil wrapped vials (pre-baked at $425{ }^{\circ} \mathrm{C}$ for $12 \mathrm{~h}$ ). Approximately $50 \mathrm{~mL}$ of DEHP-containing eluate (95\% acetonitrile, 5\% water) were collected per each $1.1 \mathrm{~kg}$ butter sample. Prior to further analyses, the volume of each eluate was reduced to $1 \mathrm{~mL}$ by rotary evaporation and the residual again dissolved in 2 $\mathrm{mL}$ of hexane. Method blanks were prepared using this same set of procedures.

Prior to AMS, the carbon mass and purity of DEHP in each of the (2-mL, in hexane) butter sample extracts was determined by GC-EIMS with a series of standard petrogenic DEHP $\left(99.8 \pm 0.1 \%\right.$ pure, Supelco ${ }^{\circledR}$ Analytical, Bellefonte, PA) solutions. GC-EIMS purity was determined from peak areas of the total ion chromatogram, and by threedimensional deconvolution within the DEHP peak to determine co-eluting compounds (see Table 1). These analyses were performed with a $1-\mu \mathrm{L}$ injection, $1.00 \mathrm{~mL} / \mathrm{min}$ column flow of helium, initial temperature of $90^{\circ} \mathrm{C}$, increasing by $15^{\circ} \mathrm{C} / \mathrm{min}$ for $20 \mathrm{~min}$. EIMS ion spectra were collected from 50 to $500 \mathrm{~m} / \mathrm{z}$ at a scan rate of $3.3 \mathrm{scans} \mathrm{s}^{-1}$. Up to 21 co-eluted compounds were identified in the GC-EIMS spectra by matching against the NIST GC-EIMS standard spectral library. On average, three compounds, Z, E-2, 13 octadecadien-1-ol, cholesterol, and siloxanes, accounted for approximately 17\%, 20\% and 58\%, respectively, of the total co-eluted carbon mass. Siloxanes observed were 
consistent with GC-column bleeding and were, therefore, not included in purity and mass determinations. The apparent carbon fraction of DEHP (carbon purity), carbon mass in DEHP $\left(m_{D E H P}\right)$ and method blank $\left(m_{D E H P, m t d}\right)$, and mass of carbon in identified coeluting compounds $\left(m_{\text {icoe }}\right)$ were determined from the GC-EIMS spectra. These are listed in Table 1 for each isolate sample to facilitate ${ }^{14} \mathrm{C}$ corrections described below.

\subsection{Carbon Isotopes Measurements and Corrections}

Five of the weighed samples were transferred to pre-combusted $\left(550^{\circ} \mathrm{C}\right)$, Al-foilwrapped quartz tubes (20-cm, $1 / 4$ inch o.d.), after removing the hexane by rotary evaporation, and were sealed with pre-baked, Swagelok ${ }^{\circledR}$ stainless steel union fittings fitted with $5-\mathrm{cm}, 1 / 4$ inch o.d. glass rods to prevent leakage or contamination during shipment to LLNL for measurement of total C mass $\left(m_{L L N L}\right)$ by manometry and fraction modern $\left(f_{m}\right)$ using LLNL's FN-Class AMS system as described previously (Nelson et al., 2013).

In addition, three $260 \mathrm{mg}(0.5-\mathrm{mL})$ aliquots of a $250 \mathrm{ppm}$ solution of the Supelco ${ }^{\circledR}$ DEHP standard in hexane were prepared for AMS to assess carbon contamination occurring after the final chromatography step, herein defined as $m_{\text {postHPLC, }}$ as described below. The spiked method blanks and the diluted petrogenic standard solutions (dPSS) aliquots were shipped separately to LLNL for AMS, to prevent cross contamination. In our work, the appropriate contemporary carbon reference material is the raw butter itself. Accordingly, two 0.9-mg aliquots of raw butter were packaged and shipped to LLNL for AMS. Lastly, to correct AMS-reported $f_{m}$ values $\left(f_{m \text {,reported }}\right)$ for isotopic fractionation, carbon-13 
fractionation $\left(\delta^{13} C\right)$ was measured at the University of Maryland using "elemental analyzer" isotope ratio mass spectrometry (EA-IRMS) (Isoprime Ltd, Manchester, UK).

To determine $f_{m}$ of carbon in DEHP extracted from butter for each sample i, $f_{m, \text { reported }}$ values for the samples must be corrected for the radiocarbon content of all impurities, $j$, as follows.

$$
f_{m, D E H P_{i}}=\frac{f_{m, \text { reported }} \cdot m_{L L N L}-\sum_{j=1}^{n}\left(f_{m} \cdot m\right)_{j}}{m_{D E H P_{i}}}
$$

where $f_{m, D E H P_{i}}$ is the true fraction of modern carbon in DEHP extracted from each butter sample; $m_{D E H P_{i}}$ is the mass of carbon contained in DEHP extracted from the butter as obtained from the analytical GCMS measurements. $\left(f_{m} \cdot m\right)_{j}$ is the product of the carbon mass and $f_{m}$ of the $j^{\text {th }}$ of $\mathrm{n}$ impurities. Herein, masses of three impurities were determined: i.e., $m_{D E H P, m t d}, m_{i c o e}$ and a third component, designated extra carbon mass, $m_{\text {extra }}$, was calculated for each sample as the difference between carbon masses analytically determined in the samples (i.e., $m_{D E H P_{i}}+m_{D E H P, m t d_{i}}+m_{\text {icoe }_{i}}$ ) and the manometrically determined mass, $m_{L L N L}$. Note that Eq. 1 is a ${ }^{14} \mathrm{C}$ mass balance equation, as $m^{14} \mathrm{C}$ is, in each case, the product of a total carbon mass $(m)$ and its corresponding fraction modern $\left(f_{m}\right)$. Analogous ${ }^{14} \mathrm{C}$ - mass balance equations were used to calculate the carbon masses and modern fractions of two components of $m_{\text {extra }}$, as described below.

The fraction of contemporary carbon $\left(f_{c}\right)$ (Reddy, Pearson, Xu, McNichol, Benner, Wise, et al., 2002) was computed by normalizing the $f_{m, D E H P}$ value for each sample to the fraction modern measured for the raw butter $\left(f_{m, b t r}\right)$ and multiplying by the isotope fractionation correction factor (Nelson, Ondov, VanDerveer, \& Buchholz, 2013) for the 
DEHP and whole butter, as follows.

$$
f_{c}=\frac{f_{m, D E H P}}{f_{m, b t r}} \cdot \frac{1-2 \cdot \frac{\delta^{13} c_{D E H P}}{1000}}{1-2 \cdot \frac{\delta^{13} c_{b t r}}{1000}}
$$

\section{Results and Discussion}

\subsection{Carbon Masses}

Total carbon masses determined by manometry, the masses of DEHP in isolates and method blanks, and those in identified coeluted compounds determined by GCMS are listed in Table 1. Also listed in Table 1 are values of $f_{m, \text { reported }}$ and ${ }^{13} \mathrm{C}$ fractionations $\left(\delta^{13} C_{D E H P}\right.$, expressed relative to Vienna Pee Dee Belemnite (VPDB) as per convention) for each of the five DEHP isolates (B1-B5). Measured carbon masses (mDEHP,APSS and $\left.m_{L L N L, d P S S}\right)$ and their modern carbon fractions $\left(f_{m, \text { reported,dPSS }}\right)$ reported for the diluted petrogenic DEHP standard solutions are listed in Table 2. Table 3 contains mass and $f_{m}$ values used to calculate the modern fraction of extra carbon mass $\left(f_{m, \text { extra }}\right)$. Fractions of modern $\left(f_{m, D E H P}\right)$ and contemporary $\left(f_{c, D E H P}\right)$ carbon in DEHP extracted from the butter samples are listed in Table 4.

Carbon masses in DEHP determined in the butter samples (B1-B5, $2^{\text {nd }}$ column of Table 1) ranged from a low of 71 to $122 \mu \mathrm{g}$, i.e., in a favorable range for accurate radiocarbon analysis (the lower limit of the FN-Class AMS used herein is typically user-blank-limited to $\approx 15 \mu \mathrm{g})$. Method blank DEHP masses $(\approx 1 \mu \mathrm{g})$ were reasonably small, and the masses of identified coeluted compounds, 2.3 to $9.8 \mu \mathrm{g}$, accounted for only 3 to $7 \%$ of the total identified compound masses in the isolates in accordance with the apparent carbon purity 
(column 4). However, extra (unidentified) carbon masses ( $\left.m_{\text {extra }}\right)$, ranging from $64 \pm 7$ to $154 \pm 9 \mu \mathrm{g} \mathrm{C}$ in four of the extracts, and $906 \pm 26 \mu \mathrm{g} \mathrm{C}(91.5 \%$ of the $\mathrm{C})$ in the fifth extract (B5) analyzed by AMS, were far more substantial.

As indicated in Table 2, 33.3 $\pm 2.5 \mu \mathrm{g}(\mathrm{n}=3,1 \sigma) \mathrm{C}$ of extra carbon mass was detected in the diluted petrogenic DEHP standards (dPSS1, dPSS2, dPSS3) as determined by mass balance. Because the diluted petrogenic standards were not subjected to any of the extraction or chromatography steps, this extra carbon mass can only be attributed to incomplete evaporation of the solvent prior to combustion/graphitization or contamination resulting from post-HPLC handling before and after shipping and is, therefore, labeled $m_{\text {postHPLC. }}$ As indicated in Table 2, its corresponding fraction modern $\left(f_{m, p o s t H P L C}\right)$ was calculated after correction for the mass of the petrogenic DEHP standard "spike" using the carbon mass and ${ }^{14} \mathrm{C}$ mass balance equations shown in Table 2. The corresponding mean and standard deviation of $f_{m, p o s t H P L C}, 0.021 \pm 0.005(\mathrm{n}=3,1 \sigma)$, is both small and uniform enough to be consistent with a predominance of unevaporated petrochemical solvent. Thirty-microgram amounts of unevaporated hexane far exceed hexane's azeotropic concentration in a solution of hexane and DEHP, despite the fact that a turbo pump was used to remove solvent. Therefore it appears that evaporation is kinetically hindered.

Clearly, $m_{\text {extra }}$ must contain at least one other component, which for reasons discussed below, we assigned to unidentified coeluted compounds associated with the butter, $m_{\text {extra,btr, i.e., }}$

$$
m_{\text {extra }}=m_{\text {post } P L C}+m_{\text {extra,btr }}
$$


As indicated in Table 3, values of $m_{\text {extra,btr }}$ calculated using Eq. 3 ranged from 31 to 873 $\mu \mathrm{g}$. The largest value is that of sample B5 and accounts for $96.3 \%$ of $m_{\text {extra }}$ for this sample. Moreover, $f_{m \text {,reported }}, 0.941 \pm 0.003$, indicates that it is predominately comprised of modern (or contemporary) carbon. As approximately $78 \%$ of butter is composed of triglycerides (USDA National Nutrient Database for Standard Reference, Release 20, 2007), the most likely contemporary component is undetected coeluting triglycerides (most of which have from 30 to 64 carbon atoms, whereas DEHP has only 24). Accordingly, the value of $f_{m, e x t r a, b t r}$ was taken to be that measured for whole butter, i.e., 1.0561. With all masses in Eq. 3 known, we calculated $f_{m \text {,extra }}$ for each butter sample using the ${ }^{14} \mathrm{C}$ mass balance equation shown in Table 3 .

\subsection{Error Analysis}

The uncertainties in $f_{m, D E H P}$ and $f_{c, D E H P}$ were calculated by error propagation using the total differential method with all cross terms and, because uncertainties were fully accumulated. As indicated in Table 2 and Table 3, uncertainties in many of the calculated values were quite large, e.g., $f_{m \text {,postHPLC }}$ and $f_{m, \text { extra. }}$. Therefore Monte Carlo (MC) simulations were introduced to recalculate the fraction modern and its uncertainty for each sample. In these simulations, all of the calculations described above were used to construct a MATLAB ${ }^{\circledR}$ function in which 50,000 normally distributed pseudo-random perturbations were made independently on the full set of 30 input variables for each of

the 5 samples. Results of both methods are listed in Table 4 , wherein $f_{m, D E H P} \mathrm{~S}$ and $f_{c, D E H P}$ s are the mean of the 50,000 calculations. The Monte Carlo derived uncertainties were uniformly much less than those derived by the total differential method. 
It seems clear that the reason for the substantially lower uncertainties obtained by the MC method is that it can effectively couple extremes of the distribution. The total differential (TD) method does not. In the TD method cross product terms are typically smaller than the squared terms: i.e., the square of a fraction is generally larger than the product of uncertainties of different absolute values. Applied to a complicated error analysis where uncertainties in many of the input values are large the TD method can lead to an over or underestimation of the uncertainties, because it never couples uncertainties in different wings of the distribution. Accordingly, we deem the mean and standard deviations of $f_{c}$ values calculated with $\mathrm{MC}$ to be more accurate. Nevertheless, the Monte Carlo means (of the 50,000 calculations) for each sample were nearly identical to the computed values for both $f_{m, D E H P}$ and $f_{c, D E H P .}$. Therefore the mean and standard deviation of $f_{c, D E H P}$ for DEHP in the 5 butter isolates, i.e., $0.16 \pm 0.12(\mathrm{n}=5,1 \sigma)$, are nearly identical to those for the total differential method, i.e., $0.17 \pm 0.12(n=5,1 \sigma)$.

\section{Conclusion}

Radiocarbon isotope analysis was successfully applied to determine the contemporary fraction of carbon in DEHP in market butter, a fatty food matrix, at a level of only $1 \mathrm{ppm}$. The results demonstrate that $84 \pm 12 \%$ of the DEHP isolated is petrogenic, despite the fact that DEHP-containing wrapping materials are no longer used. These results are comparable, but less than the fraction of contemporary carbon $(0.235 \pm 0.073)$ recently reported by Nelson et al. (Nelson, Ondov, VanDerveer, \& Buchholz, 2013) for DEHP isolated from Stilton cheese. It is noteworthy that penicillium is used to make Stilton cheese, and this fungus might possibly be responsible for its larger fraction of contemporary carbon. 
Despite the finding that more than $64 \mu \mathrm{g}$ of extra carbon were contained in each of the DEHP isolates from butter, the fraction of contemporary carbon could be determined with a sufficient degree of accuracy to be useful to agencies responsible for monitoring and regulating the food supply system. Nevertheless, future work should be undertaken to reduce the amounts of extra carbon observed in the current method.

Acknowledgements: This work was funded by the Joint Institute for Food Safety and Applied Nutrition (JIFSAN), grant \# U01FD001418. This work performed in part under the auspices of the U.S. Department of Energy by Lawrence Livermore National Laboratory under Contract DE-AC52-07NA27344. Support was provided by NIGMS 8P41GM103483.We sincerely thank all the above institutes for their support. 


\section{References}

Agency for Toxic Substances and Disease Registry. (2002). Toxicological Profile for Di(2-ethylhexyl)phthalate. In). Atlanta, GA: Department of Health and Human Services, Public Health Service.

Alderson, N. (2008). Bisphenol-A (BPA), Statement of Norris Alderson, Ph.D., Congressional Testimony before the Subcommittee on Commerce, Trade and Consumer protection House Committee on Energy and Commerce, http://www.fda.gov/NewsEvents/Testimony/ucm115235.htm. In). U.S. FDA.

Amade, P., Mallea, M., \& Bouaicha, N. (1994). Isolation, structural identification and biological activity of two metabolites produced by Penicillium olsonii Bainier and Sartory. J. Antibiotics, 47(2), 201-207.

Chen, C. Y. (2004). Biosynthesis of di-(2-ethylhexyl) phthalate (DEHP) and di-n-butyl phthalate (DBP) from red alga-Bangia atropurpurea. Water Research, 38(4), 1014-1018.

Department of Health and Human Services. (2011). Report on Carcinogens, Twelfth Edition (2011). In, (pp. 156).

Eglinton, T. I., Benitez-Nelson, B. C., Pearson, A., McNichol, A. P., Bauer, J. E., \& Druffel, E. R. M. (1997). Variability in Radiocarbon Ages of Individual Organic Compounds from Marine Sediments. Science, 277(5327), 796-799.

European Chemicals Bureau. (2008). European Union Risk Assessment Report Bis (2ethylhexyl) Phthalate (DEHP). In, vol. 80). Luxembourg: Office for Official Publications of the European Communities, 2008: European Chemicals Bureau. 
Giust, J. A., Seipelt, C. T., Anderson, B. K., Deis, D. A., \& Hinders, J. D. (1990). Determination of bis (2-ethylhexyl) phthalate in cow's milk and infant formula by high-performance liquid chromatography. Journal of Agricultural and Food Chemistry, 38(2), 415-418.

Hayashi, S., Asakawa, Y., Ishida, T., \& Matsuura, T. (1967). Phthalate Esters of Cryptotaenia Canadensis DC. Var. Japonica Makino. Tetrahedron Letter, 50, 5061-5063.

Hirosawa, N., Yano, K., Suzuki, Y., \& Sakamoto, Y. (2006). Endocrine disrupting effect of di-(2-ethylhexyl)phthalate on female rats and proteome analyses of their pituitaries. Proteomics, 6(3), 958-971.

Huber, W. W., Grasl-Kraupp, B., \& Schulte-Hermann, R. (1996). Hepatocarcinogenic potential of di(2-ethylhexyl)phthalate in rodents and its implications on human risk. Crit Rev Toxicol, 26(4), 365-481.

Ito, Y., Yamanoshita, O., NAsaeda, N., Tagawa, Y., Lee, C.-H., Aoyama, T., Ichihara, G., Furuhashi, K., Kamijima, M., Gonzles, F. J., \& Nakajima, T. (2007). Di(2ethylhexyl)phthalate induces hepatic tumorigenesis through a peroxisome proliferator-activated receptor a-independent pathway. Journal of Occupational Health, 49, 172-182.

Koch, H. M., Bolt, H. M., \& Angerer, J. (2004). Di(2-ethylhexyl)phthalate (DEHP) metabolites in human urine and serum after a single oral dose of deuteriumlabelled DEHP. Archives of Toxicology, 78(3), 123-130.

Koo, H. J., \& Lee, B. M. (2004). Estimated exposure to phthalates in cosmetics and risk assessment. J Toxicol Environ Health A, 67(23-24), 1901-1914. 
Kotowska, U., Garbowska, K., \& Isidorov, V. (2006). Distribution coefficients of phthalates between absorption fiber and water and its using in quantitative analysis. Analytica Chimica Acta, 560(1-2), 110-117.

Lottrup, G., Andersson, A. M., Leffers, H., Mortensen, G. K., Toppari, J., Skakkebaek, N. E., \& Main, K. M. (2006). Possible impact of phthalates on infant reproductive health. Int J Androl, 29(1), 172-180; discussion 181-175.

Namikoshi, M., Fujiwara, T., Nishikawa, T., \& Ukai, K. (2006). Natural abundance C-14 content of dibutyl phthalate (DBP) from three marine algae. Marine Drugs, 4(4), 290-297.

Nelson, M. A., Ondov, J. M., VanDerveer, M. C., \& Buchholz, B. A. (2013). Contemporary Fraction of Bis (2-ethylhexyl) Phthlate in Stilton Cheese by Accelerator Mass Spectrometry. Radiocarbon, 55(2-3), 686-697.

Nerin, C., Cacho, J., \& Gancedo, P. (1993). Plasticizers from printing inks in a selection of food packagings and their migration to food. Food Additives \& Contaminants, 10(4), 453-460.

Orsi, D. D., Gagliardi, L., Porrà, R., Berri, S., Chimenti, P., Granese, A., Carpani, I., \& Tonelli, D. (2006). A environmentally friendly reversed-phase liquid chromatography method for phthalates determination in nail cosmetics. Analytica Chimica Acta, 555(2), 238-241.

Pocar, P., Fiandanese, N., Secchi, C., Berrini, A., Fischer, B., Schmidt, J. S., Schaedlich, K., \& Borromeo, V. (2012). Exposure to di(2-ethyl-hexyl) phthalate (DEHP) in utero and during lactation causes long-term pituitary-gonadal axis disruption in male and female mouse offspring. Endocrinology, 153(2), 937-948. 
Rais-Bahrami, K., Nunez, S., Revenis, M. E., Luban, N. L., \& Short, B. L. (2004).

Follow-up study of adolescents exposed to di (2-ethylhexyl) phthalate (DEHP) as neonates on extracorporeal membrane oxygenation (ECMO) support.

Environmental Health Perspectives, 112(13), 1339-1340.

Reddy, C. M., Pearson, A., Xu, L., McNichol, A. P., Benner, B. A., Wise, S. A., Klouda, G. A., Currie, L. A., \& Eglinton, T. I. (2002). Radiocarbon as a Tool To Apportion the Sources of Polycyclic Aromatic Hydrocarbons and Black Carbon in Environmental Samples. Environmental Science \& Technology, 36(8), 1774-1782.

Rudel, R. A., Gray, J. M., Engel, C. L., Rawsthorne, T. W., Dodson, R. E., Ackerman, J. M., Rizzo, J., Nudelman, J. L., \& Brody, J. G. (2011). Food packaging and bisphenol A and bis (2-ethyhexyl) phthalate exposure: findings from a dietary intervention. Environmental Health Perspectives, 119(7), 914.

Sharman, M., Read, W. A., Castle, L., \& Gilbert, J. (1994). Levels of di-(2ethylhexyl)phthalate and total phthalate esters in milk, cream, butter and cheese. In Food Addit Contam 1994/05/01 ed., vol. 11 (pp. 375-385).

U.S. Department of Agriculture. (2013). Composition of Foods Raw, Processed, Prepared USDA National Nutrient Database for Standard Reference, Release 26. In): U.S. Department of Agriculture.

Zhou, Y., Chen, F., \& Li, Z. (2002). Prediction of Eluotropic Sequence of Solutes in Countercurrent Chromatography. Chinese Journal of Chromatography, 20(6), 526-529. 
Table 1 Carbon masses, purities, and isotope fractionation of butter isolates and identified components

\begin{tabular}{|c|c|c|c|c|c|c|c|c|}
\hline $\begin{array}{c}\text { Sample } \\
\text { ID }\end{array}$ & $\begin{array}{c}m_{D E H P} \\
(\mu g)^{a}\end{array}$ & $\begin{array}{c}m_{D E H P, m t d} \\
(\mu g)^{b}\end{array}$ & $\begin{array}{c}\text { Carbon } \\
\text { Purity by } \\
\text { GCMS (\%) }\end{array}$ & $\begin{array}{l}m_{\text {icoe }} \\
(\mu g)\end{array}$ & $\begin{array}{c}m_{G C M S} \\
(\mu g)\end{array}$ & $\begin{array}{c}m_{L L N L} \\
(\mu g)^{c}\end{array}$ & $\delta^{13} C_{D E H P}$ & $f_{m, \text { reported }}{ }^{d}$ \\
\hline B1 & $86 \pm 6$ & $1.1 \pm 0.1$ & $93.5 \pm 1.8$ & $5.9 \pm 1.8$ & $93 \pm 6$ & $247 \pm 6$ & $-24.6 \pm 1.9$ & $0.648 \pm 0.003$ \\
\hline B2 & $122 \pm 8$ & $0.7 \pm 0.1$ & $92.5 \pm 1.2$ & $9.8 \pm 1.7$ & $133 \pm 8$ & $200 \pm 5$ & $-27.7 \pm 1.9$ & $0.296 \pm 0.002$ \\
\hline B3 & $76 \pm 6$ & $0.8 \pm 0.1$ & $97.1 \pm 0.8$ & $2.3 \pm 0.6$ & $79 \pm 6$ & $143 \pm 4$ & $-27.7 \pm 1.9$ & $0.305 \pm 0.003$ \\
\hline B4 & $71 \pm 5$ & $0.9 \pm 0.2$ & $96.5 \pm 0.7$ & $2.6 \pm 0.5$ & $75 \pm 5$ & $221 \pm 6$ & $-25.2 \pm 1.9$ & $0.667 \pm 0.003$ \\
\hline B5 & $80 \pm 6$ & $0.9 \pm 0.2$ & $95.6 \pm 1.2$ & $3.7 \pm 1.1$ & $84 \pm 6$ & $990 \pm 25$ & $-23.4 \pm 1.9$ & $0.941 \pm 0.003$ \\
\hline
\end{tabular}

${ }^{\mathrm{a}}$ Determined with GC-EIMS; $1 \sigma$ uncertainty, $\mathrm{n}=3$.

${ }^{\mathrm{b}}$ Determined with GC-EIMS; $1 \sigma$ uncertainty, $\mathrm{n}=3$; The values of $\mathrm{B} 4$ and $\mathrm{B} 5$ were the average value of $\mathrm{B} 1$, $\mathrm{B} 2$ and B3, because the corresponding method blanks were neither measured with GC-EIMS nor AMS.

${ }^{\mathrm{c}}$ Determined by $\mathrm{CO}_{2}$ pressure-volume manometry; $1 \sigma$ uncertainty; $\mathrm{n}=1$.

'The mean and uncertainty of two "whole" butter samples was $1.0561 \pm 0.0022$.

Table 2 Mass Balance data for determining $f_{m, p o s t H P L C}$ from diluted petrogenic DEHP standard solution (dPSS)

\begin{tabular}{|c|c|c|c|}
\hline \multicolumn{4}{|c|}{ Measured Values $^{a}$} \\
\hline $\begin{array}{l}\text { Sample } \\
\text { ID }\end{array}$ & $\begin{array}{c}m_{D E H P, d P S S} \\
(\mu \mathrm{g})\end{array}$ & $\begin{array}{c}m_{L L N L, d P S S} \\
(\mu \mathrm{g})\end{array}$ & $f_{m, r e p o r t e d, d P S S}$ \\
\hline $\begin{array}{l}\text { dPSS1 } \\
\end{array}$ & $47 \pm 1$ & $78 \pm 2$ & $0.011 \pm 0.005$ \\
\hline dPSS2 & $48 \pm 1$ & $81 \pm 2$ & $0.008 \pm 0.005$ \\
\hline dPSS3 & $47 \pm 1$ & $83 \pm 2$ & $0.009 \pm 0.005$ \\
\hline \multirow{2}{*}{\multicolumn{4}{|c|}{$\begin{array}{l}{ }^{\mathrm{a}} f_{m} \text { of the petrogenic DEHP standard }(200 \mu \mathrm{g})=0.000 \\
\text { Table } 3 \text { Mass balance data for determining }\end{array}$}} \\
\hline & & & \\
\hline $\begin{array}{c}\text { Sample } \\
\text { ID }\end{array}$ & $m_{\text {extra }}(\mu \mathrm{g})$ & $\begin{array}{c}m_{\text {extra,bt }} \\
(\mu \mathrm{g})\end{array}$ & $f_{m, e x t r a}$ \\
\hline B1 & $154 \pm 9$ & $121 \pm 9$ & $0.83 \pm 0.08$ \\
\hline B2 & $67 \pm 10$ & $34 \pm 10$ & $0.55 \pm 0.18$ \\
\hline B3 & $64 \pm 7$ & $31 \pm 7$ & $0.52 \pm 0.13$ \\
\hline B4 & $146 \pm 8$ & $113 \pm 8$ & $0.82 \pm 0.07$ \\
\hline B5 & $906 \pm 26$ & $873 \pm 26$ & $1.02 \pm 0.04$ \\
\hline
\end{tabular}


Table $4 f_{m, D E H P}$ and $f_{c, D E H P}$ for Butter isolates with total differential method and Monte Carlo simulation.

\begin{tabular}{|c|c|c|c|c|}
\hline \multirow[b]{2}{*}{$\begin{array}{l}\text { Sample } \\
\text { ID }\end{array}$} & \multicolumn{2}{|c|}{$\begin{array}{c}\text { Total differential } \\
\text { method }\end{array}$} & \multicolumn{2}{|c|}{ Monte Carlo simulation } \\
\hline & $f_{m, D E H P}$ & $f_{c, D E H P}$ & $f_{m, D E H P}$ & $f_{c, D E H P}$ \\
\hline B1 & $0.28 \pm 0.19$ & $0.27 \pm 0.18$ & $0.28 \pm 0.07$ & $0.27 \pm 0.07$ \\
\hline B2 & $0.09 \pm 0.12$ & $0.09 \pm 0.11$ & $0.09 \pm 0.07$ & $0.08 \pm 0.07$ \\
\hline B3 & $0.09 \pm 0.13$ & $0.09 \pm 0.12$ & $0.09 \pm 0.09$ & $0.09 \pm 0.09$ \\
\hline B4 & $0.33 \pm 0.19$ & $0.32 \pm 0.18$ & $0.33 \pm 0.07$ & $0.31 \pm 0.07$ \\
\hline B5 & $0.06 \pm 0.65$ & $0.06 \pm 0.62$ & $0.06 \pm 0.10$ & $0.05 \pm 0.10$ \\
\hline
\end{tabular}

